\title{
A Simple Technique to Remove Well Fixed Porous Cementless Acetabular Component in Revision Total Hip Arthroplasty
}

\author{
Naren Garneti, MRCS, MSc (Tr), MCh (Orth), FRCS (Tr \& Orth)* \\ Consultant Orthopaedic Surgeon, Rotherham General Hospital, The Rotherham NHS Foundation Trust, United Kingdom
}

\begin{abstract}
Removing well-fixed porous cementless acetabular components in revision Total Hip arthroplasty can be a surgical challenge for Orthopaedic surgeons. Forceful removal can result in loss of bone stock. Acetabular wall fracture is a real risk associated with extracting well-fixed cementless acetabular components, especially with certain instruments. Extraction of a well-fixed porous cementless acetabular component with relative ease can be achieved with the technique described.

I report a technique of disrupting the implant-bone interface. This technique is simple and safe, with no risk of complications like bone loss or acetabular wall fractures. Acetabular bone stock is preserved, making it easier to implant revision components.
\end{abstract}

To my knowledge, this technique has never been described before. I have used this technique in my practice for the extraction of well-fixed porous acetabular components for a variety of indications. The results have been reproducible with no complications, like acetabular wall fractures or bone loss, requiring adjuvant fixation with augments.

Keywords

Cementless acetabular components, Revision Hip arthroplasty

\section{Introduction}

The most commonly used cementless acetabular components are porous, modular, hemispherical, press-fit or line-toline-fit metallic shells with polyethylene, metal or ceramic liners locked into the metal shell. Acetabular component design variations can present a surgical challenge for component removal. Instruments designed to follow the hemispherical contour of the acetabular component may not always be suitable in the presence of secondary augments like screws, fins, pegs and spikes.

The primary goal in cementless acetabular component removal is minimization of bone loss or destruction, fractures and preserving as much host bone as possible for fixation of the revision component. The design of the instruments and their ability to disrupt the bone-implant interface safely will have an impact on the degree of host bone destruction and the incidence of wall fractures during acetabular component extraction in revision hip surgery.

Several techniques have been described for the extraction of cementless acetabular components. Some of these techniques are common to both cemented and press-fit acetabular components, while others are specific to one or the other [1-5].
I describe a technique to extract a well-fixed cementless porous acetabular component using simple instruments to disrupt the implant-bone interface, making it easy to extract the acetabular component. This technique can be used to extract well-fixed cementless acetabular components irrespective of the brand of the acetabular prosthesis. This technique is simple, efficient, inexpensive and conserves bone stock.

\section{Surgical Technique}

A key principle in removal of well-fixed cementless ace-

*Corresponding author: Mr. Naren Garneti, MRCS, MSc (Tr), MCh (Orth), FRCS (Tr \& Orth), Consultant Orthopaedic Surgeon, Rotherham General Hospital, The Rotherham NHS Foundation Trust, Moorgate Road, Rotherham S60 2UD, South Yorkshire, United Kingdom, Tel: 077-992-688-27

Accepted: June 01, 2021

Published online: June 03, 2021

Citation: Garneti N (2021) A Simple Technique to Remove Well Fixed Porous Cementless Acetabular Component in Revision Total Hip Arthroplasty. J Orthop Surg Tech 4(1):315-318 


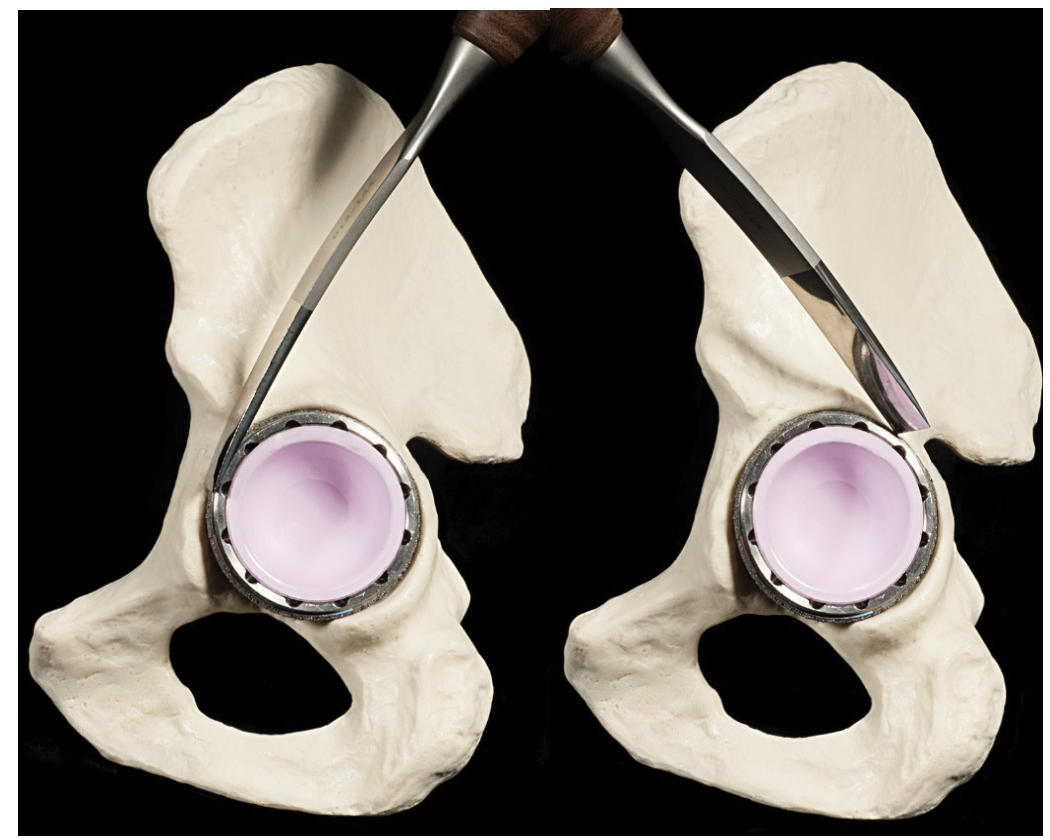

Figure 1: $(a, b)$ Acetabular margins cleared using hemispherical osteotomes.
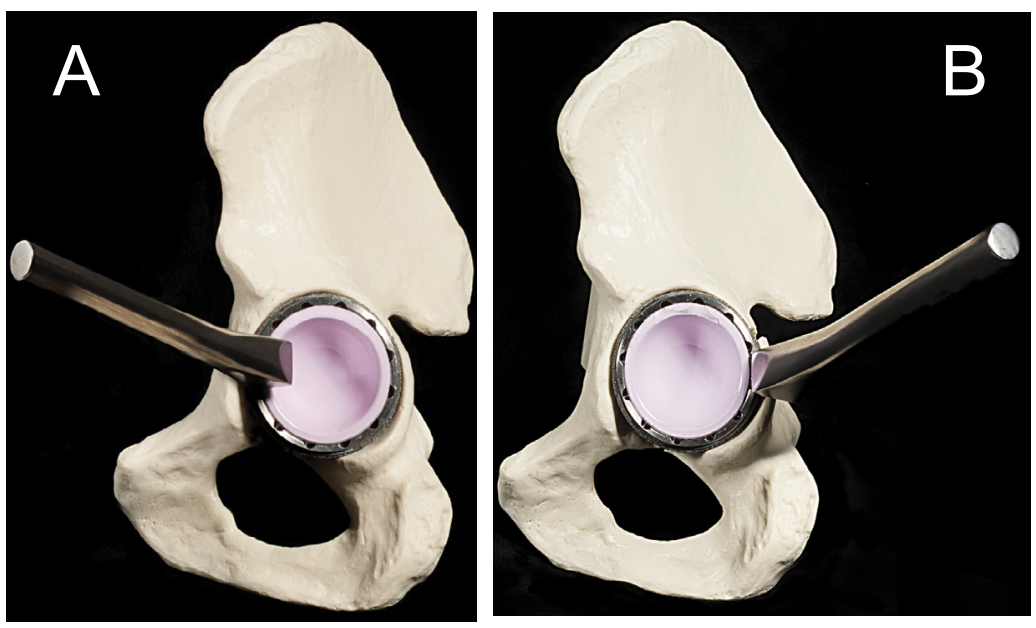

Figure 2: $(a, b)$ The acetabular component tapped in several quadrants using the serrated osteotome.

tabular components is to safely disrupt the implant-bone interface, which permits removal of the component.

Adequate exposure, especially in obese patients, using any surgical approach to the hip joint, which can be made extensile to increase the working space if required, is recommended for this technique. I use the posterior approach in my practice.

The liner does not have to be removed with this technique, unless there are screws or pegs that need removal prior to extracting the cup. However, it is important to avoid damage to the liner to prevent formation of third body wear particles.

The margins of the acetabular component should be exposed circumferentially before the process of extracting the implant is commenced. This process is facilitated by using the right-sided and left-sided curved, hemispherical osteotomes or even offset chisels that have a hemispherical contour, similar to the implanted acetabular component (Figure 1a and Figure 1b).

The acetabular component is then tapped in several quadrants using the serrated punch or an osteotome (Figure $2 \mathrm{a}$ and Figure 2b). After several taps, the acetabular component is tapped in a clock-wise/ anti-clockwise direction and finally in a retrograde manner using a sharp or a blunt osteotome with a serrated tip (Figure 3a, Figure 3b, Figure $3 c$ and Figure $3 d)$. These maneuvers should disrupt the implant-bone interface with no bone loss or fractures of the acetabular walls. The process is repeated, alternating the above two maneuvers if required. The cup should fall out with relative ease (Figure $4 \mathrm{a}$ and Figure $4 \mathrm{~b}$ ). The key to successful extraction of the porous acetabular component is the safe disruption of the bone-implant interface. 

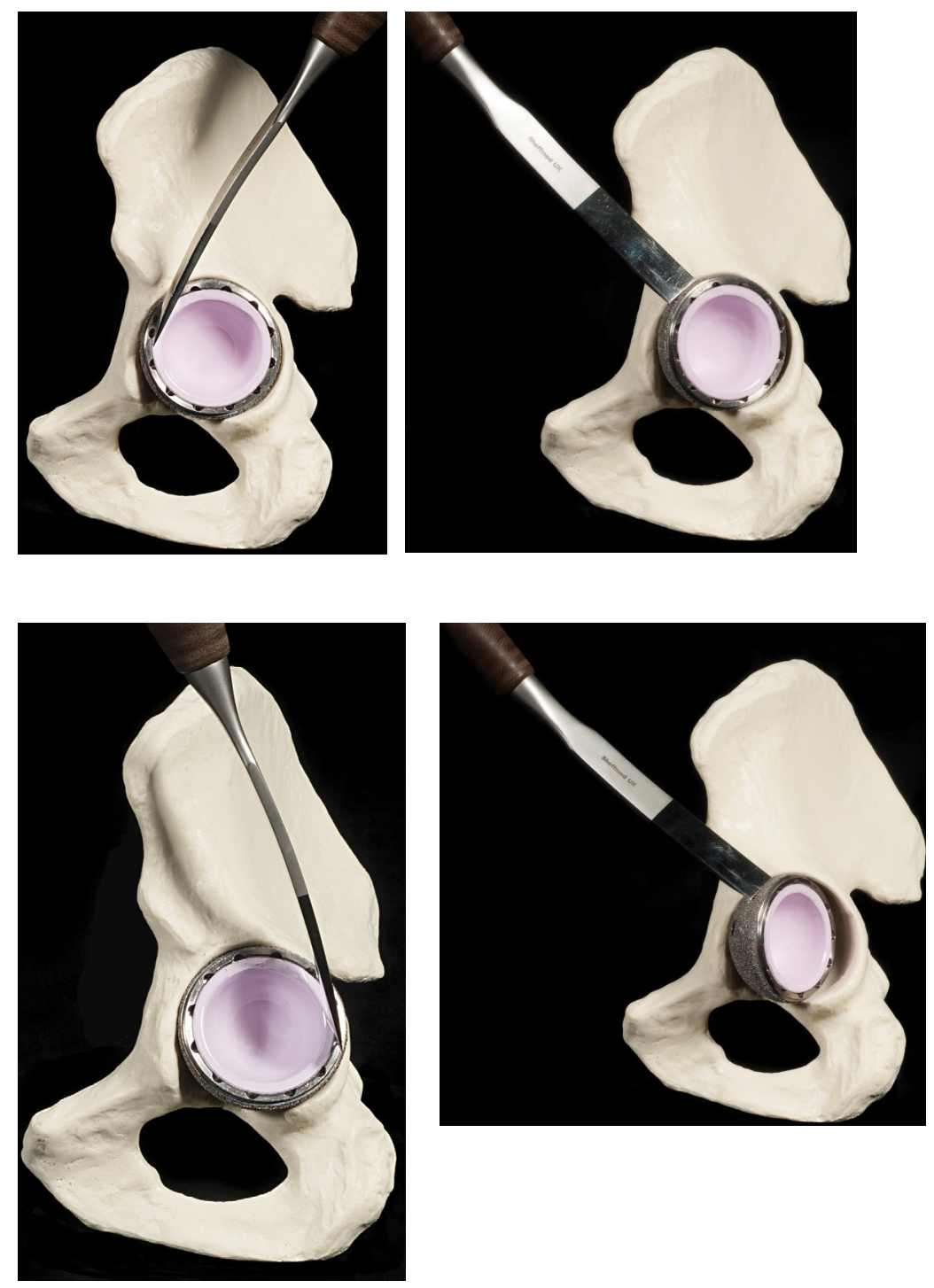

Figure 3: $(a, b, c, d)$ Acetabular component tapped in a clock-wise/anti-clockwise direction and finally in a retrograde manner using a sharp or a blunt osteotome with a serrated tip.

\section{Discussion}

Attempting to disrupt the implant-bone interface using cutting blades is technically challenging, may require considerable force and can result in extensive bone loss and acetabular wall fractures [6]. On occasions, it may still be difficult to extract the acetabular component if islands of Osseo integrated surface of the acetabular component remains intact, either due to inadequate or improper use of the cutting blades of different lengths. Instruments with cutting blades that are used to disrupt the implant-bone interface may have to be modified to make them safe and effective to achieve their objectives $[7,8]$. With the technique described, the implant-bone interface is safely disrupted with the use of osteotomes, punches and a hammer, by tapping the margin of the cup in different quadrants and then in a clockwise/anti-clockwise direction.

The concept of using screws is not new and can be used successfully to remove polyethylene liners in revision hip arthroplasty $[9,10]$.
Zhang, et al. described a technique of drilling a tunnel on the postero-superior quadrant of acetabulum, from the bone cortex to the surface of acetabular metal cup [11]. Whilst this technique may seem relatively simple, it can result in weakening of the posterior wall of the acetabulum. It could also result in a significant amount of bone loss, posterior acetabular wall fracture, as the implant-bone interface is not disrupted before extraction of a cementless acetabular component.

The technique described above is safe, reliable and inexpensive. The risk of bone loss and fracture of the acetabulum are unlikely to occur with this technique. Surgeon is in control of the technique. Just three simple instruments will aid in extraction of a well-fixed cementless acetabular component with relative ease. The curved osteotomes, serrated punches and the blunt serrated tipped osteotomes either could be added to the standard Orthopaedic instrument tray or could be packed separately.

In my experience, this technique has worked reliably and consistently over the years. Even the press-fit acetabular cups 

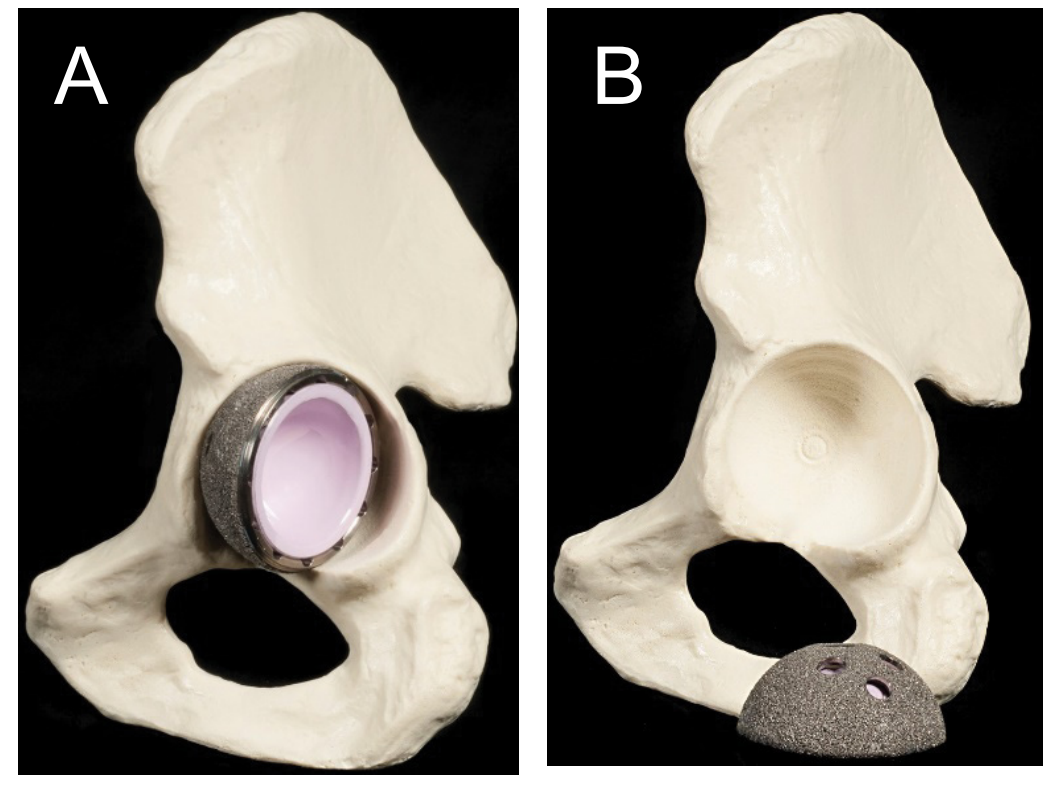

Figure 4: $(a, b)$ Acetabular cup should fall out with relative ease.

without peripheral notches can be removed by creating a notch with appropriate blunt or serrated tipped instruments. Perhaps the only limitation with this technique is encountered when the acetabular component is massively under-sized and lies deep within the acetabulum with significantly over-hanging acetabular margin.

\section{Summary}

Extraction of a well-fixed cementless acetabular component can be a surgical challenge in Revision Hip Arthroplasty. The technique described above to extract a well-fixed cementless acetabular component is a simple, efficient and inexpensive. Bone stock is preserved and the risk of complications like fractures is unlikely with this technique.

\section{Acknowledgment}

I wish to acknowledge Isobel Saunders for the illustrations.

Isobel Saunders, Clinical Photographer, Medical Illustration Department, Rotherham General Hospital, The Rotherham NHS Foundation Trust, United Kingdom

\section{References}

1. Judas FM, Dias RF, Lucas FM (2008) A technique to remove a well-fixed titanium coated RM. Acetabular cup in revision hip arthroplasty. J Orthop Surg Res 20: 317.

2. Olyslaegers C, Wainwright T, Middleton RG (2008) A novel technique for the removal of well-fixed cementless, large-diameter metal-on-metal acetabular components. J Arthroplasty 23: 1071-1073.
3. Taylor PR, Stoffel KK, Dunlop DG, et al. (2009) Removal of the well-fixed hip resurfacing acetabular component: A simple, bone preserving technique. J Arthroplasty 24: 484-486.

4. Daum WJ, Calhoun JH (1988) Removal of the acetabular component minimizing destruction of the bone bed. J Arthroplasty 3: 379-380.

5. Markovich GD, Banks SA, Hodge WA (1999) A new technique for removing noncemented aceta-bular components in revision total hip arthroplasty. Am J Orthop 28: 35-37.

6. Mitchell PA, Masri BA, Garbuz DS, et al. (2003) Removal of wellfixed, cementless, acetabular components in revision hip arthroplasty. J Bone Joint Surg Br 85: 949-952.

7. MA Bhutta, Gambhir A (2009) Using the Explant Acetabular Cup Removal System for removing a well-fixed resurfacing cementless acetabular component. Ann R Coll Surg Engl 91: 344.

8. Rawal JS, Soler JA, Rhee JS, et al. (2010) Modification of the Explant system for the removal of well fixed hip resurfacing sockets. J Arthroplasty 25: 1170.

9. Judas FM, Lucas FM, Fonseca RL (2015) A technique to remove a stable allpolyethylene cemented acetabular liner in revision hip arthroplasty: A case report. Int J Surg Case Rep 9: 54-56.

10. Kassim M, Pai SK, Ashworth M (2008) The world's longest instrument-an aid to acetabular cup extraction in revision hip surgery. Ann R Coll Surg Engl 90: 168.

11. Xiaoqi Zhang MD, Fei Hu MD, Rui He MD, et al. (2017) A simple technique to remove well-fixed acetabular components in revision of total hip arthroplasty. Arthroplast Today 3: 251-252.

DOI: $10.36959 / 453 / 565$

Copyright: (C) 2021 Garneti N. This is an open-access article distributed under the terms of the Creative Commons Attribution License, which permits unrestricted use, distribution, and reproduction in any medium, provided the original author and source are credited. 